\title{
Risk factors for low birthweight in the public-hospitals at Peshawar,
} NWFP-Pakistan

\author{
Sareer Badshah*1, Linda Mason², Kenneth McKelvie ${ }^{3}$, Roger Payne ${ }^{4}$ and \\ Paulo JG Lisboa ${ }^{5}$
}

Address: ${ }^{1}$ Deprtment of Statistics, Islamia College, University of Peshawar, Pakistan, ${ }^{2}$ School of Applied Community and Social Studies, Liverpool John Moores University, Liverpool, UK, ${ }^{3}$ Formerly School of Computing and Mathematical Sciences, Liverpool John Moores University Liverpool, UK, ${ }^{4}$ Biomathematics and Bioinformatics Department, Rothamsted Research, Harpenden, Herts, AL5 2JQ, UK and ${ }^{5}$ School of Computing and Mathematical Sciences, Liverpool John Moores University Liverpool, UK

Email: Sareer Badshah* - Sareerbadshah@yahoo.com; Linda Mason - L.Mason1@ljmu.ac.uk; Kenneth McKelvie - mckelvie@liverpool.ac.uk; Roger Payne - Roger.Payne@bbsrc.ac.uk; Paulo JG Lisboa - P.J.Lisboa@ljmu.ac.uk

* Corresponding author

Published: 4 June 2008

BMC Public Health 2008, 8:197 doi:10.1/86/147|-2458-8-197
Received: 14 June 2007

Accepted: 4 June 2008

This article is available from: http://www.biomedcentral.com/I47/-2458/8//97

(c) 2008 Badshah et al; licensee BioMed Central Ltd.

This is an Open Access article distributed under the terms of the Creative Commons Attribution License (http://creativecommons.org/licenses/by/2.0), which permits unrestricted use, distribution, and reproduction in any medium, provided the original work is properly cited.

\begin{abstract}
Background: Low birthweight is a widely used indicator of newborn health. This study investigates the association of birthweight $<2.5 \mathrm{~kg}$ (LBW) with a wide range of factors related to geo-demographics, maternal health and pregnancy history in public hospitals at Peshawar, North West Frontier Province (NWFP) Pakistan. It is noted that that Low birthweight may arise for two different reasons, one related to gestational age and the other corresponding to births that are small for gestational age (SGA).

Methods: Data on geo-demographics, maternal health indicators, pregnancy history and outcome scores for newborn babies and their families $(n=1039)$ were collected prospectively between August and November 2003 in a cross-sectional survey of four public hospitals in Peshawar, NWFP-Pakistan. Crude and adjusted odds ratios were used to investigate the factors affecting incidence of LBW, by multivariate logistic regression. Gestational age was included as an explanatory variable therefore the additional covariates identified by model selection are expected to account for SGA.

Results: The main geo-demographic risk factors for SGA identified in this study, controlling for gestational age of less than 37 weeks, are maternal age, nationality and consanguinity. Presentation with anaemia and the history of previous abortion/miscarriage were also found to be significant independent factors. The adjusted odds ratio for gestational age showed the largest effect in explaining the incidence of LBW. The next highest odds ratio was for maternal age below 20 years. The explanatory model included two pairwise interactions, for which the predicted incidence figures for LBW show an increase among the Tribal area with presentation of anaemia, and among full term babies with their mothers having a previous history of abortion/miscarriage.

Conclusion: In addition to gestational age, specific factors related to geo-demographics (maternal age, consanguinity and nationality), maternal health (anaemia) and pregnancy history (abortion/miscarriage) were significantly associated with the incidence of LBW observed at the four hospitals surveyed in Peshawar. These results indicate that cultural factors can adversely affect the incidence of SGA in this area of Pakistan.
\end{abstract}




\section{Background}

Across the world, neonatal mortality is 20 times more likely for low birthweight (LBW) babies compared to heavier babies $(\leq 2.5 \mathrm{~kg})[1]$. It is also established as an important risk factor for neonatal morbidity [2,3]. The cohort of LBW (birthweight $<2.5 \mathrm{~kg}$ ) babies is likely to reflect two effects, namely a short gestational age (preterm births) and small for gestational age (SGA). Small for gestational age usually results from intra-uterine growth restriction (IUGR) [4]. However, if the mother is small, it may be normal for her to have a small fetus. In the current study gestational age is included as an explanatory variable, therefore the study is focused on the identification of risk factors for the complementary effect which is SGA.

In a literature survey, de Onis et al (1998) found that IUGR babies are at increased risk of perinatal mortality and morbidity, i.e. sudden infant death syndrome, poor cognitive development and neurologic impairment, cardiovascular disease, high blood pressure, obstructive lung disease, diabetes, high cholesterol concentrations and renal damage in adulthood [4]. Such babies remain a burden on government expense in developed countries and a permanent problem for their families in developing countries.

The incidence of LBW $(<2.5 \mathrm{~kg}$ irrespective of gestational age) is estimated to be $16 \%$ worldwide, $19 \%$ in the least developed and developing countries and $7 \%$ in the developed countries. The incidence of LBW is 31\% in South Asia followed by Middle East and North Africa (15\%), Sub-Saharan Africa (14\%) and East Asia and Pacific 7\% [5]. Of the total estimated IUGR babies $(<2.5 \mathrm{~kg}$ and $=>37$ weeks), Asia accounts for $75 \%$, and with $20 \%$ and $5 \%$ born in Africa and Latin America, respectively. The IUGR accounts for $11 \%$ of the total babies in developing countries ranging from $2 \%$ to $21 \%$, that is 6 times higher compared to developed countries [4].

In South Asia the incidence of LBW is 36\%, 30\% in Bangladesh and India, and 19\% in Pakistan [5]. In Pakistan the LBW rate varies from 5\% to $23 \%$ in different parts [6-11], whilst IUGR in a community-based study in Karachi was found to be $24.4 \%$ [12].

Peshawar is the capital of the NWFP Province of Pakistan, where the health care facilities are used by the people of Settled areas of NWFP, and Federally Administered Tribal Areas of Pakistan (FATA or Tribal areas) including Afghan refugees since 1979. The diversity in area-status (Tribal/ Settled), ethnicity (Afghan refugees/Pakistani) and differential in overall geo-demographics factors suggest a need to investigate LBW in Peshawar. The current study derives an explanatory multivariate regression model for LBW, that includes gestational age as an independent covariate.
The remaining selected covariates are thus interpreted as explanatory of incidence of LBW under the category of SGA. Therefore, this prospective public hospital-based study in Peshawar focuses on LBW to investigate associated explanatory factors beyond gestational age. These factors contribute towards the explanation of the observed births that are SGA (including preterm and non-preterm SGA births).

\section{Methods}

Data were collected in a cross-sectional prospective survey on maternal and paternal geo-demographic factors, maternal health and pregnancy history (MHPH) and neonatal outcome from all public hospitals (Hayatabad Medical Complex, Khyber Teaching Hospital, Lady Reading Hospital, and Government Maternity Hospital) in Peshawar during August to November 2003 through clinicians on duty.

The research reported in the paper was approved by the Research Ethics Committee of Liverpool John Moores University, with reference number 02141. Approval was granted prior to the commencement of data collection by questionnaire. Verbal consent was obtained from each mother recruited for this study.

The data comprise questionnaire responses collected from 1,039 single birth mothers from a total of 2286 mothers delivered during the study period irrespective of birth-status and gestational age. The volunteer clinicians for this study collected data as per their usual shifts i.e. day time one week and night time the next. This gave us $45.5 \%$ of the available data. As far as possible all consecutive births during the duty periods were recruited into this study, resulting in only $4.5 \%$ records returned entirely empty. This may have been through refusal by the patient to take part in the study or an inadvertent omission on the part of the duty clinician.

Women were interviewed by the clinicians in local languages at admission in the reception, with the exception of emergency admissions, when they were interviewed in the labour room. The factors were recorded on a predesigned questionnaire validated by health professionals during a pilot study in the same hospitals.

Five factors were collected as continuous measures, which were later banded into categorical measures according to the previous literature (Table 1 and 2). These measures include maternal age [14-16], gestational age [16,17], height $[12,18]$ and the gap between this and the previous pregnancy [19]. However, the threshold for maternal pregnancy weight during analysis was chosen as $57 \mathrm{~kg}$ for this study, as this value had the highest significance in the univariate analysis for LBW. For the purpose of this paper 
Table I: Univariate analysis of geo-demographic maternal risk factors for LBW in Peshawar, 2003.

\begin{tabular}{|c|c|c|c|c|c|}
\hline \multirow[t]{2}{*}{ Variable } & & \multicolumn{2}{|c|}{ Birthweight } & \multirow[t]{2}{*}{ OR } & \multirow[t]{2}{*}{$95 \% \mathrm{Cl}$} \\
\hline & & $<2.5 \mathrm{~kg}$ & $\geq 2.5 \mathrm{~kg}$ & & \\
\hline & $(\mathrm{N}=1039)$ & $(n=10 I)$ & $(n=938)$ & & \\
\hline \multicolumn{6}{|l|}{ Area of residence } \\
\hline Tribal area & $243(24.0)$ & $34(\mid 4.0)$ & $209(86.0)$ & 1.7 & {$[1.1,2.7] *$} \\
\hline Settled area & $770(76.0)$ & $66(8.6)$ & $704(91.4)$ & & \\
\hline \multicolumn{6}{|l|}{ Water sources } \\
\hline Non-fresh & $373(36.8)$ & $49(13.1)$ & $324(86.9)$ & 1.8 & {$[1.2,2.7] * *$} \\
\hline Fresh & $64 I(63.2)$ & $5 I(8.0)$ & $590(92.0)$ & & \\
\hline \multicolumn{6}{|l|}{ Nationality } \\
\hline Afghan refugees & $120(\mid 1.7)$ & $23(19.2)$ & $97(80.8)$ & 2.5 & {$[1.5,4.2] * *$} \\
\hline Local people & $903(88.3)$ & $78(8.6)$ & $825(91.4)$ & & \\
\hline \multicolumn{6}{|l|}{ Consanguinity } \\
\hline Consanguineous & $61 \mathrm{I}(60.0)$ & $73(11.9)$ & $538(88.1)$ & 2.0 & {$[1.3,3.2] * *$} \\
\hline Non-Consanguineous & $407(40.0)$ & $26(6.4)$ & $381(93.6)$ & & \\
\hline \multicolumn{6}{|l|}{ Maternal age } \\
\hline$<20$ years & $77(7.5)$ & $25(32.5)$ & $52(67.5)$ & 6.1 & {$[3.6,10.7]$ ** } \\
\hline$>34$ years & $172(16.8)$ & $20(11.4)$ & $152(88.4)$ & 1.7 & {$[1.0,2.9]$} \\
\hline 20-34 years & $772(75.6)$ & $56(7.3)$ & $716(92.7)$ & & \\
\hline \multicolumn{6}{|l|}{ Family income } \\
\hline$<5000$ rupees & $701(69.4)$ & $80(11.4)$ & $621(88.6)$ & 1.8 & {$[1.1,2.9] *$} \\
\hline$\geq 5000$ rupees & $309(30.6)$ & $21(6.8)$ & $288(93.2)$ & & \\
\hline \multicolumn{6}{|l|}{ Maternel education } \\
\hline Illiterate & $708(69.5)$ & $81(11.4)$ & $627(88.6)$ & 2.1 & {$[1.2,3.6] * *$} \\
\hline Non-illiterate & $310(30.5)$ & $18(5.8)$ & $292(94.2)$ & & \\
\hline \multicolumn{6}{|l|}{ Paternal education } \\
\hline Illiterate & $382(37.6)$ & $47(12.3)$ & $335(87.7)$ & 1.6 & {$[1.1,2.4] *$} \\
\hline Non-illiterate & $635(62.4)$ & $52(8.2)$ & $583(91.8)$ & & \\
\hline
\end{tabular}

$*^{*} \mathrm{p}<0.01,{ }^{*} \mathrm{p}<0.05$

consanguinity was included under geo-demographic factors (Table 1). Pregnancy registration was taken as proxy for pre-natal care.

The category of LBW was defined as less than $2.5 \mathrm{~kg}$ [13]. Gestational age was calculated from the first day of the last menstrual period reported by the mother and categorised such that any delivery from 24 and $<37$ weeks were termed as preterm birth [13]. Some mothers may have had estimates of gestational age derived by ultrasound measurement made at antenatal visits, although this would not be the case for un-registered pregnancies which account for more than half of the observations.

The reliability of the estimates of gestational age was further investigated using a descriptive table showing the incidence of observations grouped by birthweight and gestational weeks, shown in the form of a normogram in Figure 1 . This also show boundaries for the lower $10^{\text {th }}$ percentile $\left(<10^{\text {th }}\right.$ percentiles) and upper $10^{\text {th }}$ percentiles ( $>90^{\text {th }}$ percentiles) of birthweight.

A comparison of the profile of birthweight against gestational age with those listed in $[20,21]$ shows a remarkable level of agreement on inspection of the two sets of data.
This is interesting to note as one set of figures was derived in a technologically advanced city from an industrialised country, and the second comes from a single hospital study in Karachi, while our figures refer to four public hospitals in a border province of Pakistan. This consistency was taken to indicate that the estimates of gestational age in the prospectively acquired data set are sufficiently good to justify a description of the LBW cohort as shown in the Table, comprising low weight births expected for gestational age and SGA, the latter including a sub group of IUGR. The analysis shown in the next section takes gestational age as an independent variable, so seek to explain the residual variations due to SGA.

From the covariates originally collected, twenty were used for the initial analysis, to keep at least 5 events (LBW) per factor, as there are 101 occurrences of LBW in the data. This ratio of events per variable is on the threshold of acceptability for the size of the pool of covariates prior to initiating the variable selection process, as recommended in the literature [22].

There were two levels of data analysis, Crude odds of LBW babies in different categories were calculated to identify the significant factors at univariate level [23]. Multivariate 
Table 2: Univariate analysis of maternal health and pregnancy history, risk factors for LBW in Peshawar, 2003.

\begin{tabular}{|c|c|c|c|c|c|}
\hline \multirow[t]{2}{*}{ Variable } & & \multicolumn{2}{|c|}{ Birthweight } & \multirow[t]{2}{*}{ OR } & \multirow[t]{2}{*}{$95 \% \mathrm{Cl}$} \\
\hline & & $<2.5 \mathrm{~kg}$ & $\geq 2.5 \mathrm{~kg}$ & & \\
\hline & $(N=1039)$ & $(n=101)$ & $(n=938)$ & & \\
\hline \multicolumn{6}{|c|}{ Gestational age } \\
\hline Preterm & $229(22.8)$ & $60(26.2)$ & $169(73.8)$ & 6.4 & {$[4.1,9.8] * *$} \\
\hline Full term & $776(77.2)$ & $4 I(5.3)$ & $735(94.7)$ & & \\
\hline \multicolumn{6}{|c|}{ Maternal diabetes } \\
\hline Yes & $27(2.7)$ & $3(11.1)$ & 24(88.9) & 1.2 & {$[0.4,3.9]$} \\
\hline No & $974(97.3)$ & $96(9.9)$ & $878(90.1)$ & & \\
\hline \multicolumn{6}{|c|}{ Maternal hypertension } \\
\hline Yes & $183(18.3)$ & $25(13.7)$ & $158(86.3)$ & 1.6 & {$[1.0,2.6]^{*}$} \\
\hline No & $816(81.7)$ & $74(9.1)$ & $742(90.9)$ & & \\
\hline \multicolumn{6}{|c|}{ Maternal anaemia } \\
\hline Yes & $383(38.5)$ & $47(12.3)$ & $336(87.7)$ & 1.5 & {$[1.0,2.3]^{*}$} \\
\hline No & $613(61.5)$ & $52(8.5)$ & $56 \mid(9 \mid .5)$ & & \\
\hline \multicolumn{6}{|c|}{ Other health conditions } \\
\hline Yes & $59(6.0)$ & $8(13.6)$ & $5 I(86.4)$ & 1.5 & {$[0.7,3.3]$} \\
\hline No & $918(94.0)$ & $87(9.5)$ & $83 I(90.5)$ & & \\
\hline \multicolumn{6}{|c|}{ Maternal height } \\
\hline$<1.55 \mathrm{mtr}$ & $310(30.8)$ & $38(12.3)$ & $272(87.7)$ & 1.4 & {$[0.9,2.2]$} \\
\hline$\geq 1.55 \mathrm{mtr}$ & $696(69.2)$ & $62(8.9)$ & $634(91.1)$ & & \\
\hline \multicolumn{6}{|c|}{ Maternal weight } \\
\hline$<57$ kg & $246(24.4)$ & $35(14.2)$ & $211(85.8)$ & 1.8 & {$[1.2,2.8] * *$} \\
\hline$\geq 57 \mathrm{~kg}$ & $763(75.6)$ & $65(8.5)$ & $698(91.5)$ & & \\
\hline \multicolumn{6}{|c|}{ Maternal BMI } \\
\hline$\leq 19.0 \mathrm{~kg} / \mathrm{m}^{2}$ & $40(4.0)$ & $4(10)$ & $36(90)$ & 1.0 & {$[0.4,2.9]$} \\
\hline$>19.0 \mathrm{~kg} / \mathrm{m}^{2}$ & $958(96.0)$ & $96(10)$ & $862(90)$ & & \\
\hline \multicolumn{6}{|c|}{ Any abortion/miscarriage ${ }^{a}$} \\
\hline Yes & $232(22.7)$ & $33(14.2)$ & 199(85.8) & 1.8 & {$[1.1,2.7] *$} \\
\hline No & $788(77.3)$ & $68(8.6)$ & $720(91.4)$ & & \\
\hline \multicolumn{6}{|c|}{ Abortion/miscarriage ${ }^{b}$} \\
\hline Yes & $172(17.2)$ & $25(14.5)$ & $147(85.5)$ & 1.7 & {$[1.1,2.8] *$} \\
\hline No & $826(82.8)$ & $74(9.0)$ & $752(91.0)$ & & \\
\hline \multicolumn{6}{|c|}{ Gap between pregnanciesc } \\
\hline$<1.5$ years & $220(33.2)$ & $25(11.4)$ & $195(88.6)$ & 1.1 & {$[0.7,1.9]$} \\
\hline$\geq 1.5$ years & $443(66.8)$ & $46(10.4)$ & $397(89.6)$ & & \\
\hline \multicolumn{6}{|c|}{ Pregnancy registration } \\
\hline No & $545(53.9)$ & $67(12.3)$ & $478(87.7)$ & 1.8 & {$[1.2,2.8] * *$} \\
\hline Yes & $467(46.1)$ & $34(7.3)$ & $433(92.7)$ & & \\
\hline
\end{tabular}

${ }^{* *} \mathrm{p}<0.01,{ }^{*} \mathrm{p}<0.05$, BMI (body mass index), a History of any abortion/miscarriage in reproductive life, $\mid{ }^{b}$ Abortion/miscarriage immediately preceding this pregnancy, c gap between this and the previous pregnancy (excluding primiparas mothers).

logistic regression $[24,25]$ was applied to uncorrelated groups of factors (Pearson's, Spearman's correlation with thresholds of 0.6), fitting the models using the software package SPSS [26] to assess the independent effects of factors on SGA [12] based on a backward stepwise approach. Wald's test was used for the significance of the factors in multivariate models [27] and chi-square was used for univariate models.

The interpretation of main effects and interactions was aided by calculating a one-way table of predicted means for each significant main effect, and a two-way table of predicted means for each significant (two-way) interaction, using the statistical package GenStat [28]. These were constructed by first forming a table containing fitted values for every combination of the seven factors in the model, then averaging over the factors that are not in the required table of predictions. This averaging was weighted using estimated population weights, formed by multiplying together a one-way table of weights for each factor, containing the proportions of cases recorded in each of its levels.

\section{Results}

The results are for data from 1039 birth episodes, prospectively sampled in the four public hospitals in Peshawar. The overall incidence of LBW $(<2.5 \mathrm{~kg})$ was found to be $9.9 \%$. However, the crude odds of LBW in all geo-demo- 


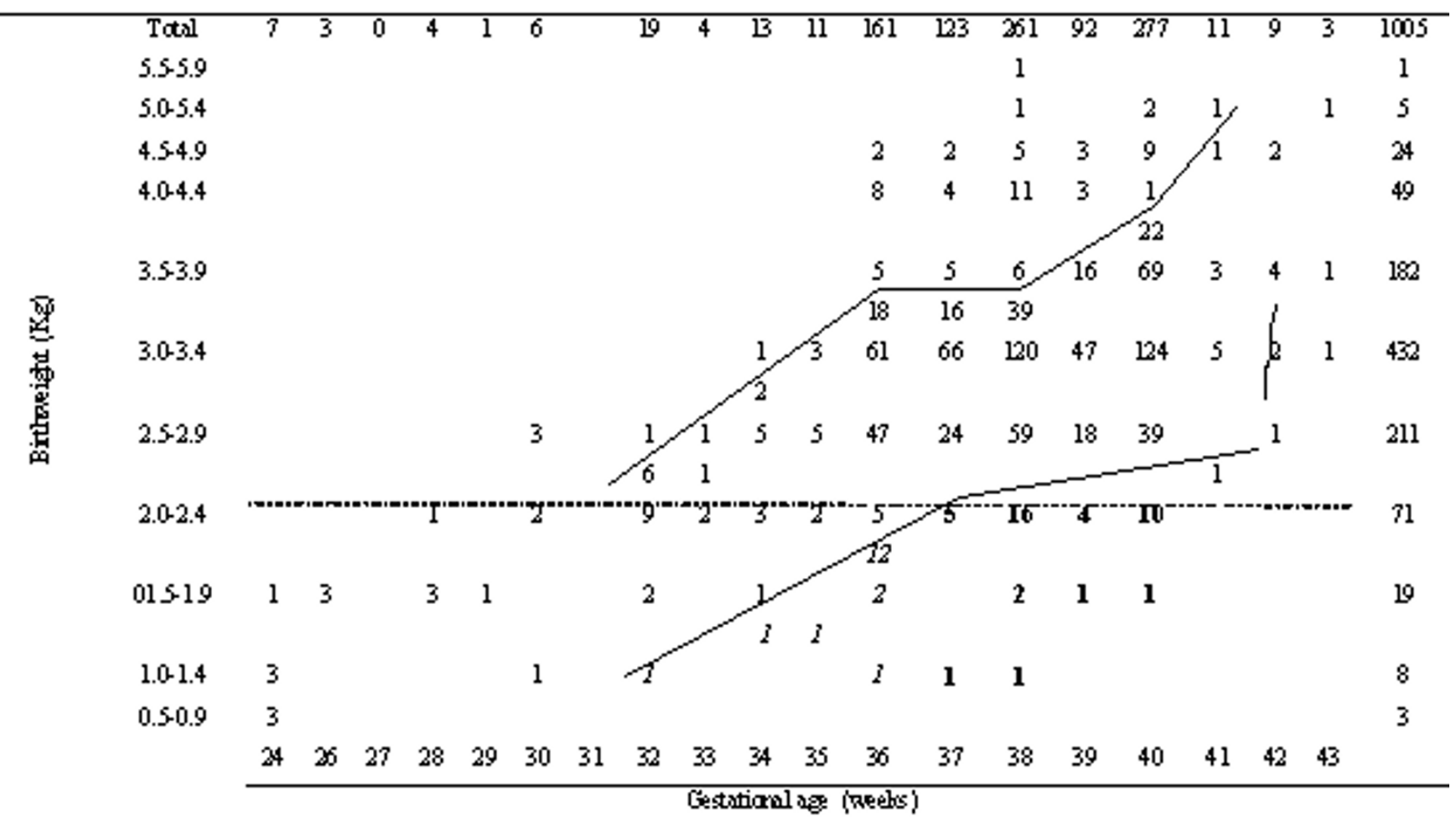

Figure I

Distribution of birth weight versus gestational age.

graphic factors (i.e. area of residence, water sources, ethnicity, consanguinity, maternal age, family income, maternal and paternal education) (Table 1), and seven other factors from MHPH (i.e. gestational age, hypertension, anaemia, maternal pregnant weight, total abortion/ miscarriage, abortion/miscarriage before this pregnancy, and maternal pregnancy registration), were found to be statistically significant at univariate level (Table 2).

In the total LBW babies, $41.6 \%(42 / 101)$ were preterm and appropriate for gestational age $\left(\geq 10^{\text {th }}\right.$ percentile, AGA), 17.8 (18/101) were preterm and small for gestational age $\left(<10^{\text {th }}\right.$ percentile, SGA) and $40.6 \%(41 / 101)$ were full term and SGA. Among the total LBW, 58.4\% (59/101) were SGA, and 40.6\% (41/101) were appropriate for gestational age (Figure 1).

\section{Results from multivariate logistic regression}

The adjusted odds of the SGA were also calculated and nine factors were found to be significant in different separate multivariable models adjusting for gestational age. Seven of these factors, namely area of residence, nationality, consanguinity, maternal age, gestational age, anaemia and abortion/miscarriage, were found to be significant risk factors for high incidence of SGA using stepwise backward logistic regression. Further analyses were carried out to identify potential interactions between the explanatory variables. This resulted in a definitive model with three geo-demographical indicators, nationality, consanguinity and maternal age at birth, and two pair-wise interactions respectively, i.e. (i) area of residence and history of anaemia, and (ii) gestational age and abortion/miscarriage (Table 3).

The adjusted odds ratios reinforce the earlier results from univariate analysis, showing that five factors significantly increase the incidence of LBW, namely Afghan refugees compared to Pakistani mothers, consanguineous compared to non-consanguineous births, and teenage compared to middle age mothers (Table 3). A further interactive term shows that anaemic mothers in Tribal areas are at increased risk of SGA compared to non-anaemic mothers in the Settled areas (Table 3). Moreover, the effect of abortion/miscarriage were seen in the case of full term babies, where the odds of SGA babied were 3.4 times higher compared to full term without abortion/miscarriages (Table 3 ).

The estimated predicted probability of LBW (PPr), obtained by marginalising over all of the explanatory variables, for single and interactive effects, respectively, are entirely consistent with the expectations from the values 
Table 3: Adjusted odds ratios and $95 \%$ confidence intervals for the final logistic regression model.

\begin{tabular}{|c|c|c|c|c|}
\hline Factors & B & AdjOR (95\% Cl) & PPr. of LBW & S. E. \\
\hline \multicolumn{5}{|l|}{ Nationality } \\
\hline Afghan refugee & 0.970 & $2.64(1.39,5.01) * *$ & 0.17 & 0.032 \\
\hline Local (Ref.) & - & - & 0.09 & 0.009 \\
\hline \multicolumn{5}{|l|}{ Consanguinity } \\
\hline Consanguineous & 0.871 & $2.39(1.39,4.12)^{* *}$ & 0.12 & 0.012 \\
\hline Non-consanguineous (Ref.) & - & - & 0.06 & 0.012 \\
\hline \multicolumn{5}{|l|}{ Maternal age } \\
\hline$<20$ years & 2.122 & $8.35(4.36,15.98) * *$ & 0.32 & 0.048 \\
\hline$>34$ years & 0.099 & $1.11(0.58,2.11)$ & 0.08 & 0.019 \\
\hline 20-34 years (Ref.) & - & - & 0.08 & 0.009 \\
\hline \multicolumn{5}{|l|}{ Interactions } \\
\hline \multicolumn{5}{|l|}{ Area $\times$ anaemia } \\
\hline [Tribal area] [Anaemia (yes)] & 1.198 & $3.3 \mathrm{I}(1.70,6.50)^{* *}$ & 0.20 & 0.035 \\
\hline [Tribal area] [Anaemia (no)] & -0.134 & $0.88(0.40,1.90)$ & 0.08 & 0.021 \\
\hline [Settled area] [Anaemia (yes)] & -0.106 & $0.90(0.49,1.65)$ & 0.08 & 0.015 \\
\hline [Settled area] [Anaemia (no)] (Ref.) & - & - & 0.09 & 0.013 \\
\hline \multicolumn{5}{|l|}{ Gestation $\times$ Abortion/miscarriage } \\
\hline [Preterm] [Abortion/miscarriage (yes)] & 2.399 & $\mid \mathrm{I} .01(5.00,24.23)^{* *}$ & 0.25 & 0.052 \\
\hline [Preterm] [Abortion/miscarriage (no)] & 2.350 & $10.49(5.73,19.20)^{* *}$ & 0.25 & 0.032 \\
\hline [Full term] [Abortion/miscarriage (yes)] & 1.209 & $3.35(1.66,6.77)^{* * *}$ & 0.11 & 0.023 \\
\hline [Full term] [Abortion/miscarriage (no)] (Ref.) & & - & 0.04 & 0.008 \\
\hline Intercept & $-4.530 * *$ & & & \\
\hline
\end{tabular}

**p $<0.01$, *p < 0.05, Ref. (Reference Category), AdjOR (Adjusted Odds Ratios), C.I (Confidence Interval), PPr. (the predicted probability of LBW from the model, or prediction for the probability of LBW in future), and S.E. (Standard Error of the predicted probability).

of the adjusted odds-ratios. The predictive analysis confirmed the significant independent effects already noted for teenage mothers, Afghan refugee mothers and consanguineous births, effect of anaemia in Tribal areas, and abortion/miscarriage on SGA (Table 3).

\section{Discussion}

This study has been conducted in public hospitals that cover only $9 \%$ (urban $=18 \%$, rural $=6 \%$ ) of the total births, whereas the majority $91 \%$ of the deliveries take place at home $(78 \%)$, or in private hospital/clinics etc (13\%) [29]. There is no proper system that can record their history at home and due to the non availability of databases this study had to recruit patients prospectively from the four main public hospitals in Peshawar. This necessarily excludes births in private hospitals, clinics and at home. Due to limited voluntary participation of clinicians, it was not possible to collect information from all mothers admitted for delivery in the four hospitals from August to November.

In the present study abortion/miscarriage was used to include induced and spontaneous abortion, "due to the taboos and sensitivity associated with reporting an induced abortion"[30]. It was not possible to interview women at their homes in privacy to separate induced and spontaneous abortion. It should be noted that pregnancy registration was used as a proxy for prenatal care. We were also unable to collect data on energy intake that might be one of the important factors in Peshawar as reported by others in developing countries [31].

Considering the reliability of the study, this study found that some of the factors, i.e. consanguinity, low family income, maternal and paternal education and non-fresh water areas, diabetes, hypertension, anaemia and abortions are comparable with other reports for population or population-based studies. However, the high ratio of mothers from Tribal areas $24 \%$ in this study, compared to the total female Tribal population 15\% [32] in this region (NWFP plus Tribal area) may over estimate, whereas, the low proportion of teenage mothers $7.5 \%$ compared to compared to $19.6 \%$ [19] may underestimate the incidence of LBW in this study.

The motivation behind this study is to collect data on low birthweight in NWFP, starting from the four public hospitals available for the general public in Peshawar. This study provides baseline information and a start to debate low birthweight from public hospitals in this region, which could help with possible intervention regarding maternal and newborn health in the future. It is an obser- 
vational study which generated a sample surveying all but a very small proportion of consecutive births attended by the clinicians who agreed to take part. While this reduced the overall sample size, the duty patterns alternated between day and night and so the stratification of sampling by clinician does not indicate any factor likely to introduce bias into the results of the study.

The overall incidence of LBW in this study at Peshawar $(10 \%)$ was half that of recent studies $(19 \%-23 \%)$ in Lahore and Karachi [7,9] and the overall national average [5]. The differential in the incidence of LBW might be due to ethnicity/racial differences in Lahore and Karachi, compared to Peshawar. However, the incidence of LBW in Budhni village near Peshawar was reported to be 5\% [6]. The variation in the present study and the Budhni village study could be due to the differences in the population based and hospital-based study. In the hospital-based study, the ratio of mothers at risk is suspected to be more prevalent than in a village study, due to referral of high risk mothers from the Basic Health Units (BHUs) based in villages. Another reason for the high incidence of LBW babies in our study compared to Northrop-Clewes study [6] could be the inclusion of mothers from Tribal areas and Afghan refugees. These mothers from Tribal areas and Afghan refugees were found to be at higher risk compared to mothers from Settled areas and Pakistani mothers, respectively.

Among the total LBW, 59\% were SGA, and 41\% appropriate for gestation (Figure 1). The main factors associated with SGA (maternal age, consanguinity, nationality, anaemia, and abortion/miscarriages) adjusting for gestational age are discussed as follows.

\section{Maternal age}

Teenage mothers are well known for adverse pregnancy outcomes. However, in this study teenage mothers were independently associated with SGA compared to middle and older age mothers. The predicted probability of SGA was estimated to be $0.32,0.08$ and 0.08 for teenage, middle age and older age mothers, respectively (Table 3 ). Furthermore, we found that teenage mothers were independently associated with low maternal weight and had low family income $(\mathrm{OR}=2.3,1.8$, $\mathrm{p}<0.01)$ compared to the middle group of maternal age.

Instead of teenage mothers, studies in Karachi and Brazil associated maternal height, weight and primiparity $[12,33]$, height, BMI and primiparity in Canada [34], and maternal weight and social status in Brazil and India $[33,35,36]$. Further studies on teenage mothers could be helpful in explaining the role of teenage mothers and its association with adverse pregnancy outcomes.

\section{Consanguinity}

Consanguinity is common in developing countries due to social, cultural and economic reasons including traditions [19] (e.g. arranged marriages influenced by parents and near relatives especially uncles and the dilemma of preserving a pure blood-line etc.). To paraphrase a common cultural perception, "first and second cousin marriage is categorized as gold and silver, whereas non-consanguineous is considered worthless". That is why, in this study the majority of the people $(60 \%)$ were found to be consanguineous, which is consistent with other community based studies in Pakistan [19,37].

In the present study, we found an independent effect of consanguinity on SGA. The impact of consanguinity in our study is consistent with other studies in Karachi [12], Pakistani Muslims in Birmingham UK [38] and the effect of genetic factors reported by Kramer in a review of adverse pregnancy outcomes [31].

\section{Afghan refugee status}

The incidence of LBW in refugee camps varies from country to country. There is evidence that in the majority of the refugee camps the incidence of LBW is less than in their country of origin and their host country [42]. We found that Afghan refugee status increased the risk of SGA. We also found that Afghan refugee mothers were less likely to avail themselves of the health resources compared to Pakistani mothers $(\mathrm{OR}=2.4, \mathrm{p}<0.01)$.

The higher incidence of adverse pregnancy outcome in Afghan refugee mothers is consistent with Vietnamese refugees in Hong Kong [38], refugees from Bosnia, Herzegovina and Serbia [40], but inconsistent with another study in Athens [41]. We suspect that the adverse outcomes in Afghan refugee mothers compared to local Pakistani mothers could be due to expected involvement of refugees in the Afghan-war that could affect pregnancy outcomes through mental health problems [43-46]. Further detailed study on Afghan refugee outcomes is recommended to understand the main causes of poor outcomes compared to Pakistani mothers.

\section{Abortion/miscarriages and anaemia}

Abortion is well-known to be among the five leading causes of maternal mortality worldwide [47]. According to an estimate, approximately 150, 000 unwanted pregnancies are terminated each day worldwide by induced abortion, about 50,000 are terminated through unsafe abortion [30]. The estimated number of terminations/ induced abortions is 890,000 annually in Pakistan, and nearly 200,000 women suffer from post-abortion complications [47]. Due to restrictive legal status in Pakistan [48], the majority of the miscarriages and induced abortions $(80 \%)$ are attended by untrained birth attendants in 
unsafe conditions $[49,50]$. The main reason behind the high number of abortions could be a desire for small family size, unplanned pregnancy, sex selective abortions/ gender preferences, or poverty [47].

In the present study, previous abortion/miscarriages were also associated independently with SGA babies (Table 3, Figure 2). It was further found that, the history of previous abortion/miscarriage were significantly higher in the hypertensive mothers during the present pregnancy than non-hypertensive mothers $(\mathrm{OR}=1.9, \mathrm{p}<0.01)$ and mothers with the history of abortion/miscarriages were at increased risk of anaemia $(\mathrm{OR}=1.5, \mathrm{p}<0.01)$ compared to mothers without history of abortion/miscarriage. The effect of previous abortions is consistent with another study in Ahmedabad [35], and other reports from developing countries [31].

Anaemia is a common problem in developing countries in pregnant women, ranging from $8 \%$ to $33 \%$ in Pakistan [51], and increases the incidence of LBW and IUGR [17]. In the present study, anaemia was $38.5 \%$ and significantly higher in Tribal and deprived areas compared to Settled and developed areas $(\mathrm{OR}=1.6,2.0, \mathrm{p}<0.01)$. We found that anaemia was one of the main causes of SGA in the Tribal area compared to non-anaemic mothers in Tribal and Settled area (Table 3, Figure 3). The effect of anaemia

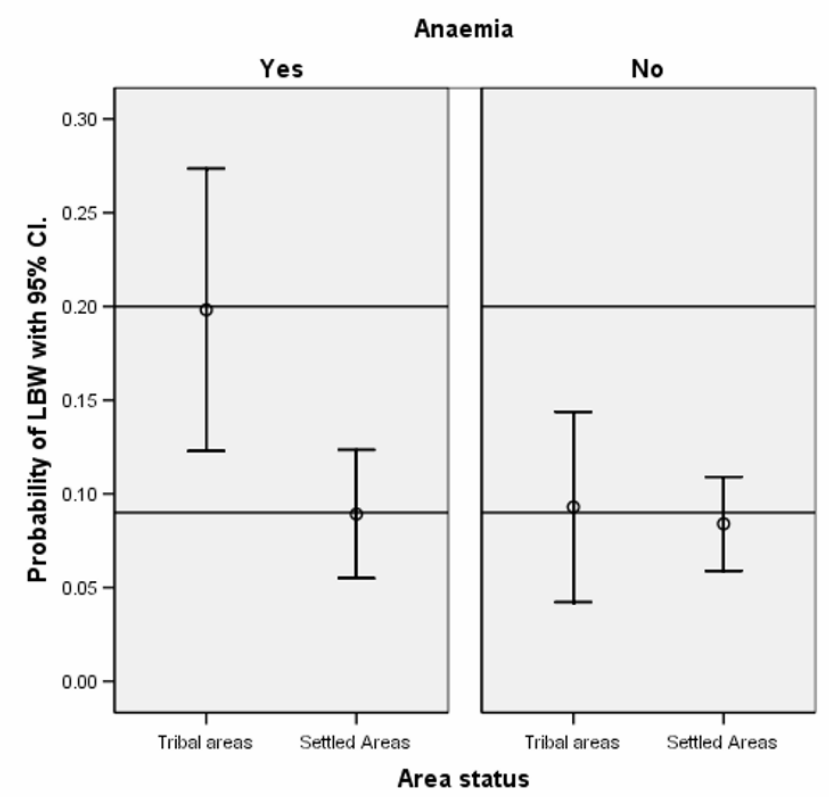

Figure 2

Distribution of LBW in Tribal and Settled areas with and without a history of anaemia during pregnancy, showing an interaction between the two explanatory variables.

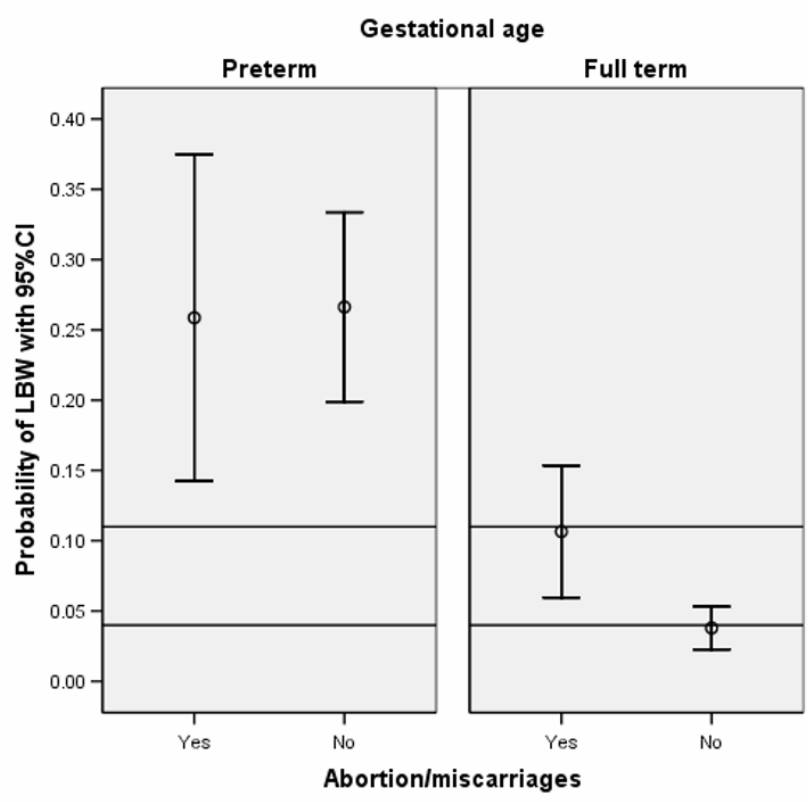

Figure 3

Distribution of LBW in preterm and full term with and without a history of previous abortion/miscarriages, indicating an effect for full-term births.

in our study is consistent with other studies in Karachi and Ahmedabad [17,35].

This study also found that, full term babies whose mothers had a history of previous abortion/miscarriage were at higher risk $(\mathrm{OR}=3.4, \mathrm{p}<0.01)$ compared to full term babies without any abortion/miscarriage (Table 3 ). Abortion affects maternal health through anaemia and haemorrhage [29], and pregnancy outcomes through low birthweight and short gestation [53]. In a hospital-based study in Calcutta-India Pahari et al [54] reported abortion as one of the main-causes of adverse pregnancy outcomes in addition to anaemia and hypertensive disorder.

\section{Conclusion}

The incidence of low birthweight reported in this study is less than one-half of the overall figure for Pakistan. However, there is significant variation among groups of mothers with specific combinations of geo-demographic factors, maternal health indicators and pregnancy history.

The effect of anaemia and previous abortion/miscarriage in Tribal areas compared to Settled areas, and the independent effect of Afghan refugee status on birth weight need further investigation to identify the root causes of adverse pregnancy outcomes in Tribal areas and Afghan refugees. 
Health awareness programmes delivered by health workers in the villages, at educational institutions and through a concerted media campaign regarding the effect of consanguinity, teenage mothers, abortions and anaemia could be helpful in reducing the adverse pregnancy outcomes.

The findings of this study are specific to public hospitals in NWFP-Pakistan. However they show value in registering with the hospital during pregnancy and potential value in improving data collection methods, perhaps by electronic means, to support the design of targeted public health interventions and monitoring of their effectiveness. Further studies on LBW in private hospitals and clinics, together with studies of home deliveries, are also needed in order to extend the scope of the present work on LBW in this region.

\section{Competing interests}

The authors declare that they have no competing interests.

\section{Authors' contributions}

SB carried out the survey, fitted the multivariate statistical model, and led the interpretation of the results and the writing of the paper. PJGL and KMcK provided supervision during the conception, design and statistical analysis. LM supervised the public health context of the work, during the conception and design of the survey as well as interpretation of the results. RP modelled the predictions using GENSTAT and verified the statistical integrity of the analysis. All authors read and approved the final version to be published.

\section{Acknowledgements}

We gratefully acknowledge the services of Dr. Lubna Hasan, Dr. Bilqis Afridi, and Dr. Falik Naz and their colleagues at the four public hospitals in Peshawar, for their help during data collection and validation of the questionnaire. We would like to thank Dr. Wahid for his co-ordination of liaisons betweens the authors and the hospital staff above. The authors would also like to pay tribute to late Professor Hamidullah for his invaluable contribution (co-ordination between doctors and authors) for this study. We also acknowledge Nazir Ahmed Chief Librarian CPSP-Karachi for sending the local literature/publication in Pakistan for this paper. We also appreciate the valuable comments of the referees that helped us in reshaping this manuscript.

\section{References}

I. UNICEF: Low Birth Weight, Country Regional and Global estimates. [http://www.unicef.org/publications/index 24840.html]. Accessed July 13, 2005

2. Borja JB, Adair LS: Assessing the net effect of young maternal age on birthweight. Am J Hum Biol 2003, 15(6):733-40.

3. Valero De Bernabé J, Soriano T, Albaladejo R, Juarranz M, Calle ME, Martínez D, Domínguez-Rojas V: Risk factors for low birth weight: a review. Eur J Obstet Gynecol Reprod Biol 2004, I I6(I):3-15.

4. de Onis M, Blossner M, Villar J: Levels and patterns of intrauterine growth retardation in developing countries. Eur J Clin Nutr 1998, 52(SuppI I):S5-15.
5. UNDP: Infants with low birth weight. [http://hdrstats.undp.org/ indicators/67.html]. Accessed December 17, 2006

6. Northrop-Clewes CA, Ahmad N, Paracha P, David IT: Impact of health services provision on mothers and infants in a rural village in North West Frontier province, Pakistan. Public Health Nutr 1998, I(I):5I-59.

7. Najmi RS: Distribution of birthweights of hospital born Pakistani infants. J Pak Med Assoc 2000, 50(4): 121-I24.

8. Naheed I, Yasin A: Determinants of low birth weight babies (A prospective study of associated factors and outcome). Ann King Edward Med Coll 2000, 6(4):36I-3.

9. Aziz S, Billoo AG, Samad NJ: Impact of socioeconomic conditions on prenatal mortality in Karachi. J Pak Med Assoc 200I, $51(10): 354-60$.

10. Khan MM: Effect of maternal anaemia on fetal parameters. J Ayub Med Coll Abbottabad 200I, 13(2):38-4I.

II. Bhutta ZA, Khan I, Salat S, Raza F, Ara H: Reducing length of stay in hospital for very low birthweight infants by involving mothers in a stepdown unit: an experience from Karachi (Pakistan). BMJ 2004, I 3;329(7475): I I5I-5.

12. Fikree FF, Berendes HW: Risk factors for term intrauterine growth retardation: a community-based study in Karachi. Bulletin of the World Health Organization 1994, 72(4):58I-587.

13. Smith GC, Pell JP, Dobbie R: Caesarean section and risk of unexplained stillbirth in subsequent pregnancy. LANCET 2003, 362(9398): 1779-1784.

14. Sathar ZA: Infant and child mortality in Pakistan-Some trends and differentials. Journal of Biosocial Science 1985, I7:35I-359.

15. Yaqoob M, Cnattingius S, Jalil F, Zaman S, Iselius L, Gustavson KH: Risk factors for mortality in young children living under various socio-economic conditions in Lahore, Pakistan: with particular reference to inbreeding. Clin Genet 1998, 54(5):426-34.

16. Khan N, Jamal M: Maternal risk factors associated with low birth weight. J Coll Physicians Surg Pak 2003, I 3(I):25-8.

17. Lone FW, Qureshi RN, Emanuel F: Maternal anaemia and its impact on perinatal outcome in a tertiary care hospital in Pakistan. East Mediterr Health J 2004, I 0(6):80I-7.

18. Pickett KE, Abrams B, Selvin S: Maternal height, pregnancy weight gain, and birthweight. Am J Hum Biol 2000, I2(5):682-687.

19. Grant JC, Bittles $\mathrm{AH}$ : The comparative role of consanguinity in infant and child mortality in Pakistan. Ann Hum Genet 1997, 6I:143-149.

20. Williams RL, Creasy RK, Cunningham GC, Hawes WE, Norris FD, Tashiro M: Fetal growth and perinatal viability in California. Obstet Gynecol 1982, 59(5):624-632.

21. Parveen Z: Birth weight percentiles by gestational age: $A$ hospital-based study. JAMC 200I, 13(2):22-27.

22. Peduzzi P, Concato J, Kemper E, Holford TR, Feinstein AR: A simulation study of the number of events per variable in logistic regression analysis. J Clin Epidemiol 1996, 49(1 2): 1373-9.

23. Dunn $G$, Everitt $B$ : Clinical Biostatistics. An Introduction to Evidence Based Medicine. Edward Arnold: London; 1995.

24. Allison Paul D: Multiple Regression: A Primer. Pine Forge Press London; 1999.

25. Kleinbaum DG: Logistic Regression: A Self-Learning Text. Springer-Verlag, London; 1994.

26. Field A: Discovering Statistics Using SPSS for Windows. Sage Publications London; 2003.

27. Machado CJ, Hill K: Early Infant Morbidity in the City of Sao Paulo, Brazil. Popul Health Metr 2003, I(I):7.

28. Payne RW, Harding SA, Murray DA, Soutar DM, Baird DB, Welham SJ, Kane AF, Gilmour AR, Thompson R, Webster R, Wilson GT: The Guide to GenStat Release 8, Part 2: Statistics. VSN International Oxfor; 2005.

29. PIHS: Pakistan Integrated House Hold Survey. Federal Bureau of Statistics, Pakistan. 2002 [http://www.statpak.gov.pk/ depts/fbs/statistics/hies0102/hies0102.html].

30. Saleem S, Fikree FF: Induced abortions in low socio-economic settlements of Karachi, Pakistan: rates and women's perspectives. J Pak Med Assoc 200I, 5 I (8):275-9.

31. Kramer MS: The epidemiology of adverse pregnancy outcomes: an overview. J Nutr 2003, I33(5 Suppl 2): I592S- I596S.

32. Statistics Division: Population Census Organization, Government of Pakistan. [http://www.statpak.gov.pk/depts/pco/statistics/ 
pop sex ratio growth rate/pop sex ratio growth rate.html]. Accessed March I3, 2007

33. Ferraz EM, Gray RH, Cunha TM: Determinants of preterm delivery and intrauterine growth retardation in North-East Brazil. Int J Epidemio 1990, I9(I): I0I-I08.

34. Kramer MS, Platt R, Yang H, McNamara H, Usher RH: Are all growth-restricted newborns created equal(ly)? Pediatrics 1999 , I03(3):599-602.

35. Mavalankar DV, Gray RH, Trivedi CR: Risk factors for preterm and term low birthweight in Ahmedabad, India. Int J Epidemiol 1992, 2 I(2):263-72.

36. Sachdev HP: Low Birth Weight in South Asia. Int J Diab Dev Ctries 200I, 2 I: I3-33.

37. Hussain $\mathrm{R}$, Bittles $\mathrm{AH}$ : The prevalence and demographic characteristics of consanguineous marriages in Pakistan. J Biosoc Sci 1998, 30(2):261-75.

38. Honeyman MM, Bahl L, Marshall T, Wharton BA: Consanguinity and fetal growth in Pakistani Moslems. Arch Dis Child 1987, 62(3):23I-5.

39. King PA, Duthie SJ, Li DF, Ma HK: Obstetric outcome among Vietnamese refugees in Hong Kong: an age-matched casecontrolled study. International Journal of Gynecology and Obstetrics 1990, 33(3):203-210.

40. Kuvacic I, Skrablin S, Hodzic D, Milkovic G: Possible influence of expatriation on perinatal outcome. Acta Obstetricia et Gynecologica Scandinavica 1996, 75(4):367-37I.

4I. Malamitsi-Puchner A, Tzala L, Minaretzis D, Michalas S, Aravantinos $D$ : Preterm delivery and low birth weight among refugees in Greece. Paediatric and Perinatal Epidemiology 1994, 8(4):384-390.

42. Hynes M, Sheik M, Wilson HG, Spiegel P: Reproductive health indicators and outcomes among refugee and internally displaced persons in postemergency phase camps. JAMA 2002, 288(5):595-603.

43. Andersson L, Sundstrom-Poromaa I, Wulff $M$, Astrom M, Bixo $M$ : Implications of antenatal depression and anxiety for obstetric outcome. Obstet Gynecol 2004, I 04(3):467-76.

44. McGinn T: Reproductive Health of War-Affected Populations: What Do We Know? International Family Planning Perspectiv 2000, 26(4): $\mid 74-179$.

45. Patel V, Rahman A, Jacob KS, Hughes M: Effect of maternal mental health on infant growth in low income countries: new evidence from South Asia. BM/ 2004, 328(7443):820-3.

46. Rahman A, Lovel H, Bunn J, Iqbal Z, Harrington R: Mothers' mental health and infant growth: a case-control study from Rawalpindi, Pakistan. Child Care Health Dev 2004, 30( I):2 I-7.

47. Population Council: Research on Unwanted Pregnancies and Post-abortion Complications in Pakistan. 2004 [http:// www.popcouncil.org/projects/RH PakResearchUnwantedPreg.html]. Accessed July 07, 2006

48. Rehan N: Attitudes of health care providers to induced abortion in Pakistan. J Pak Med Assoc 2003, 53(7):293-6.

49. Hussain $M$, Ashraf $M$, Noorani $K$ : Alleged reasons and complications of induced Abortion. I Surg Pakistan 2004, 9(3): 18-2I.

50. Khan S: Abortions: A major contributor to maternal ill health. J Pak Med Assoc 2005, 55(7):269.

51. Bhutta ZA: Why has so little changed in maternal and child health in south Asia? BMJ 32 I(7264):809-12. 2000, Sept 30

52. Steer P: The epidemiology of preterm labour. an International Journal of Obstetrics and Gynaecology 2005, I I 2(supliment I): I-3.

53. Karim SA, Bakhtawar I, Butta AT, Jalil M: Effects of first and second trimester vaginal bleeding on pregnancy outcome. J Pak Med Assoc 1998, 48(2):40-2.

54. Pahari K, Ghosh A: Study of pregnancy outcome over a period of five years in a postgraduate institute of west Bengal. I Indian Med Assoc 1997, 95(6): I72-4.

\section{Pre-publication history}

The pre-publication history for this paper can be accessed here:

\section{http://www.biomedcentral.com/1471-2458/8/197/pre} pub
Publish with Bio Med Central and every scientist can read your work free of charge

"BioMed Central will be the most significant development for disseminating the results of biomedical research in our lifetime. "

Sir Paul Nurse, Cancer Research UK

Your research papers will be:

- available free of charge to the entire biomedical community

- peer reviewed and published immediately upon acceptance

- cited in PubMed and archived on PubMed Central

- yours - you keep the copyright

Submit your manuscript here:

http://www.biomedcentral.com/info/publishing_adv.asp
BioMedcentral 